\title{
DOI: http://doi.org/10.21698/simi.2017.0020 \\ MECHANICAL RECYCLING: SOLUTIONS FOR GLASS FIBRE REINFORCED COMPOSITES
}

\author{
Victor Vladimirov ${ }^{1}$, Ioan Bica ${ }^{2}$ \\ ${ }^{1}$ Doctoral School, Technical University of Civil Engineering Bucharest, 122-124 Lacul Tei \\ Blvd, 020396, Romania, victor.vladimirov@hobas.com \\ ${ }^{2}$ Technical University of Civil Engineering Bucharest, 122-124 Lacul Tei Blvd, 020396, \\ Romania, bica@utcb.com
}

\begin{abstract}
When it comes to reutilization of glass reinforced plastic composites (GRP), mechanical recycling is one of the most widely used methods. This research brings further insight to environmental assessment of mechanical recycling by comparatively analyzing three types of products (concrete block, plastic foil and ceramic sink) from an LCA perspective. Thus, a deeper relationship between theoretical LCA modelling, factual production and market potential can be established. Results show that reutilizing GRP recyclate as replacement for petroleum-based products delivers most environmental benefits.
\end{abstract}

Keywords: GRP, LCA, mechanical recycling

\section{Introduction}

Recycling of glass reinforced plastic composites (GRP) has been gaining increasing attention. Available methods include incineration (as well as with energy recovery), co-processing, mechanical recycling and thermal recycling. Based on comparative research, mechanical recycling seems to be one of the best choices. For example, a study cross-referencing a variety of research projects on composite recycling technologies, reviewing thermal processing (pyrolysis and solvolysis) and mechanical grinding, concluded that mechanical grinding is most mature solution for glass-fibre applications (Rybicka et al. 2016). A study performed in 2009-2012, with support of the European Commission, compared incineration, mechanical recycling and thermal processing (pyrolysis and solvolysis) and revealed that solvolysis was not competitive with treatments like mechanical recycling or with incineration with energy recovery in terms of environmental impacts (EC-EURECOMP 2013). A Life-Cycle Assessment (LCA) study assessing incineration, co-processing, mechanical recycling and thermal recycling for recycling of GRP waste concluded that the mechanical approach had most environmental benefit (Vladimirov \& Bica 2017). This paper brings further detail to environmental evaluation of mechanical recycling, providing insight into three types of products (concrete block, plastic foil and ceramic sink). These applications were chosen based on existing research and market availability in order to establish a relationship between theoretical LCA modelling, market potential and factual production.

\section{Mechanical recycling}

Mechanical recycling is one of the most widely used approach for recycling GRP, with its commercial start drawing back to the 1970s (Job 2013). Applications include 
concrete, artificial wood, rubber pavement blocks, reinforcement in asphalt, dense bitumen macadam, bulk/sheet (BMC/SMC) molding compounds, textile sandwich structures, sanitary ceramic objects and plastic applications. The process typically starts by reducing the particle size of waste through mechanical operations such as shredding, crushing or milling. The resulting scrap pieces can then be separated by using sieves and cyclones into powdered products (rich in resin) and fibrous products (rich in fibers) (Yazdanbakhsh \& Bank 2014).
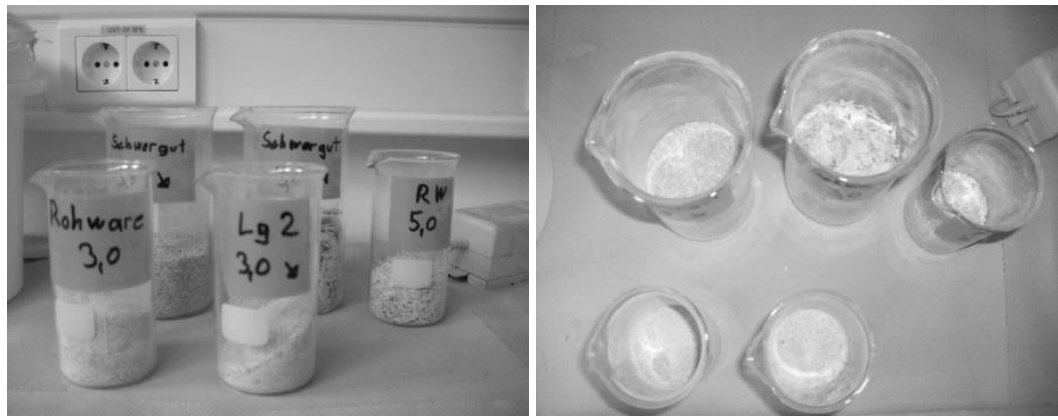

Figure 14. Fine ground GRP

Source: HOBAS

Advantages of mechanical recycling include a high variety of product applications and very positive variations of environmental indicators through recycling. Further benefits are relatively no atmospheric pollution by gas emission, simpler equipment required and no use of chemical solvents when compared with the ovens necessary for thermal processing (Ribeiro et al. 2014). Furthermore, mechanical recyclate has lower density and may contribute to lighter end-products (Pickering 2006). Drawbacks of mechanical recycling refer lack of consistency (and purity degree) of the grind material due to the many variety of GRP compound formulations. The recyclate addition to new products has tendency to negatively affect the mechanical properties of the final composite (i.e. consistency, strength, stiffness, the filler-matrix interface bond strength, etc.) and to negatively impact the cost balance (as operational costs with mechanical recycling and sorting outweigh the market value of the virgin products chopped glass fibre and calcium carbonate) (Yazdanbakhsh \& Bank 2014). Due to lower mechanical properties powder recyclates have limited potential for reuse back into the thermoset compounds from which they originated (closed loop recycling). Another potential disadvantage is that the energy content is not recovered.

\section{Mechanical reclaiming for concrete applications}

One the most extensive research work has been carried out on Portland cement concrete in which mechanically recycled GRP waste have been incorporated either as reinforcement, aggregate or filler replacement (Ribeiro et al. 2014). The use of GRP waste in concrete can therefore contribute to cost savings associated with waste handling, transport, storage and traditional disposing methods such as landfill. GRP waste substitution to fine aggregates in concrete could save approximately $15 \%$ of the fine aggregate cost (Asokan et al. 2009). 


\section{Mechanical reclaiming for plastic applications}

GRP recyclate could be used for a variety of plastic products, such as wood flooring in high density polyethylene (HDPE), PP under-floor vents or PE and PP plastic foil. In case of the foil, the powder is mixed with additives for increasing compatibility with the PE or PP base material. The addition leads to a thinner and stronger endproduct used for several applications (roofing sheet, valley gutters and flat sheet for signage) (Job 2013). Thus, the manufacturer needs less virgin material to reach the same specifications and the new product is partly "green".

\section{Mechanical reclaiming for ceramic applications}

Mold applications can be obtained in preparing a mixture comprising fragments of fiberglass, polyester resin, titanium dioxide, microspheres of thermoplastic material and benzoyl peroxide with a catalyst. The mixture is poured into a mold and then hotpressed to form an object. The ground material is usually $35-40 \%$ between $75 \%$ of weight (Wolf 2008). A similar method incorporates fine ground GRP (particles of up to $2,5 \mathrm{~mm}$ ) into granular compounds with synthetic resin (i.e. unsaturated polyester, epoxy, polyurethane, vinyl ester, etc.), essences (chemical additives for odors), zinc stearate (facilitates mixture flow) and coloring agents (Bravo et al. 2014).

\section{Methods}

Calculations were made in accordance to EN 15804 with Module D. The model used as reference is one-meter GRP Pipe with a nominal diameter (DN) $1000 \mathrm{~mm}$, pressure class one PN 1 bar and a nominal stiffness (SN) $10000 \mathrm{~N} / \mathrm{m}^{2}$. The environmental impacts were calculated as the sum of the following components (the "integrated formula: (i) primary material input, (ii) secondary material input, (iii) material recycling, (iv) energy recovery and (v) disposal. The following EN 15804 system stages were included: product stage (A1 raw material supply, A2 transport, A3 manufacturing, including treatment of factory waste), end of life (C2 transport, C3 waste processing, $\mathrm{C} 4$ disposal) and benefits and loads beyond the system boundary (module D). Module D was calculated as in the formula below (Wolf \& Chomkhamsri 2014):

$$
\begin{aligned}
& \text { Net benefit impact indicator }=\text { Yield } * \text { Amount } *\left[R R *\left(E v '-E r^{\prime}\right)-\right. \\
& R C *(E v-E r)]
\end{aligned}
$$

where RR = Recycling rate at the end-of-life (EoL stage), Ev' = Impacts of substituted virgin material production (EoL stage) (credit), Er' = Impacts connected to the recycling processes from beyond the system boundary (after the end-of waste state up to the point of functional equivalence), $\mathrm{RC}=$ Recycled content (product stage), $\mathrm{Ev}=$ Impacts of virgin material production (product stage), $\mathrm{Er}=$ Impacts connected to the recycling processes from beyond the system boundary of the life cycle that generated the waste flow (after the end-of waste state).

The system boundaries are presented in the figures below. Benefits from incineration with energy recovery of production waste were calculated for all scenarios. 


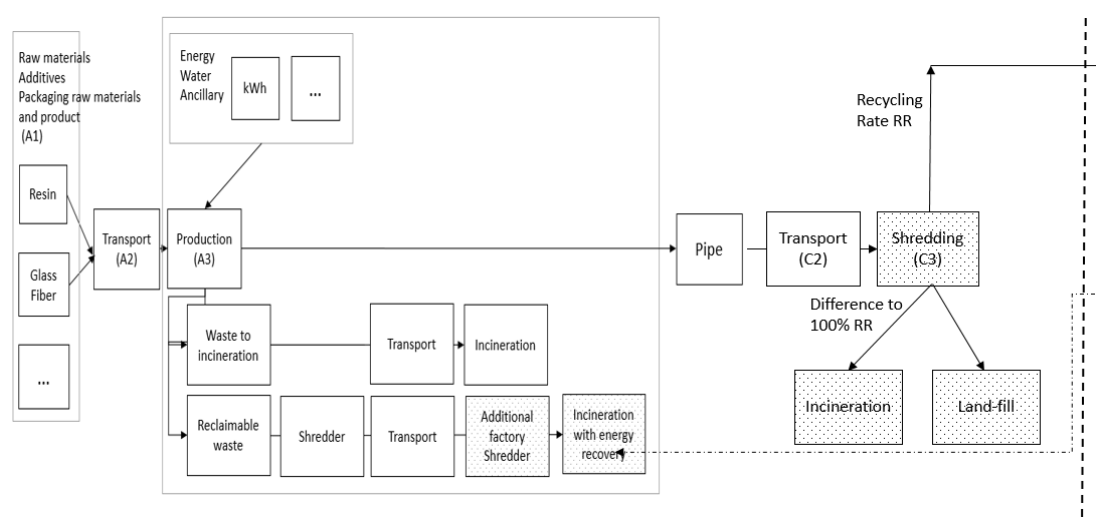

Figure 2. Base model (before Module D)

Figure 3. Module D

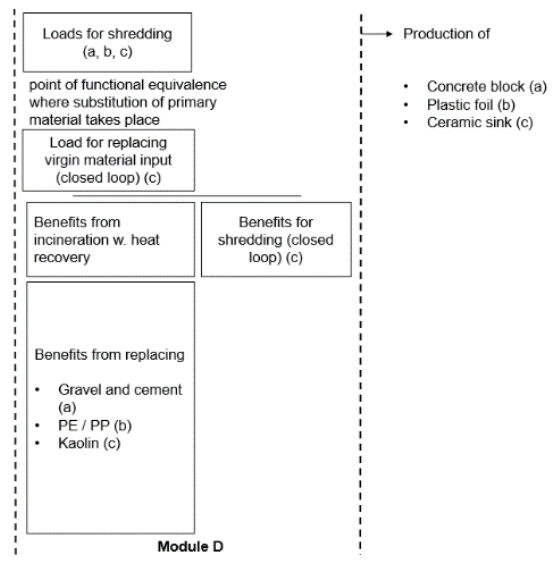

As the substitution of primary material by the secondary material is not 1 to 1 , a yield of functional equivalence of 0.85 was defined. Within system boundary 100:0 allocation was used. A 95\% recycling rate (RR) was considered to highlight the potential environmental benefits of the recycling methods. A 5\% RR was also calculated for the plastic foil scenario, to clarify the influence of the recycling rate to the results. The remaining waste (difference to recycling rate) was treated as 55\% to landfill and 45\% to incineration (EC 2016). A 90\% efficiency rate for the incineration process as well as a $300-\mathrm{km}$ distance to the incineration plant / landfill / recycling plant were included in the calculations. For the ceramic sink, two additional scenarios were calculated: (i) open loop - close loop (OL CL) in which 5\% (recycled content $\mathrm{RC}$ ) of the recyclate is used back to pipe production and (ii) using of recycled PET resin on the input side of the pipe production model. These two scenarios bring additional insight to the results, per life cycle assessment methodology. 


\section{Results and Discussion}

Results of the scenarios are presented in the Table 2 and Fig. 4. The table shows the variation of the calculated values to the reference (scenario without recycling). The figure depicts weighted results, with equal weighting factor 1 . The purpose is to facilitate the overall understanding of the results and support primary decision making amongst the discussed options.

Table 2. Results of the mechanical recycling modules

\begin{tabular}{l|cccccc}
\hline \multicolumn{1}{l}{} & $\begin{array}{c}\text { non- } \\
\text { hazardo } \\
\text { us waste }\end{array}$ & $\begin{array}{c}\text { acidif. } \\
\text { potential }\end{array}$ & $\begin{array}{c}\text { GWP } \\
\mathbf{1 0 0 a}\end{array}$ & $\begin{array}{c}\text { eutroph. } \\
\text { potential }\end{array}$ & $\begin{array}{c}\text { high } \\
\text { NOx } \\
\text { POCP }\end{array}$ & $\begin{array}{c}\text { depletion } \\
\text { abiotic } \\
\text { resources }\end{array}$ \\
\hline $\begin{array}{l}\text { Concrete } \\
\text { block (a) }\end{array}$ & $131.91 \%$ & $91.95 \%$ & $82.23 \%$ & $96.78 \%$ & $96.96 \%$ & $98.56 \%$ \\
$\begin{array}{l}\text { Plastic foil (b) } \\
\text { Ceramic sink } \\
\text { (c) }\end{array}$ & $111.26 \%$ & $-69.23 \%$ & $-41.10 \%$ & $54.11 \%$ & $-58.29 \%$ & $-158.34 \%$ \\
$\begin{array}{l}\text { Ceramic sink } \\
\text { PET (c) }\end{array}$ & $123.02 \%$ & $92.04 \%$ & $104.69 \%$ & $87.99 \%$ & $97.68 \%$ & $92.68 \%$ \\
$\begin{array}{l}\text { Ceramic sink } \\
\text { OL CL (c) }\end{array}$ & $131.80 \%$ & $90.80 \%$ & $98.39 \%$ & $80.79 \%$ & $92.38 \%$ & $93.09 \%$ \\
$\begin{array}{l}\text { Plastic foil RR } \\
5 \% \text { (b) }\end{array}$ & $774.60 \%$ & $107.17 \%$ & $150.50 \%$ & $150.82 \%$ & $131.74 \%$ & $93.88 \%$ \\
Reference & $100.00 \%$ & $100.00 \%$ & $100.00 \%$ & $100.00 \%$ & $100.00 \%$ & $100.00 \%$ \\
Reference & $9.18 \mathrm{E}-02$ & $3.35 \mathrm{E}-03$ & $1.09 \mathrm{E}+00$ & $9.17 \mathrm{E}-04$ & $2.05 \mathrm{E}-04$ & $1.01 \mathrm{E}-02$ \\
\hline
\end{tabular}

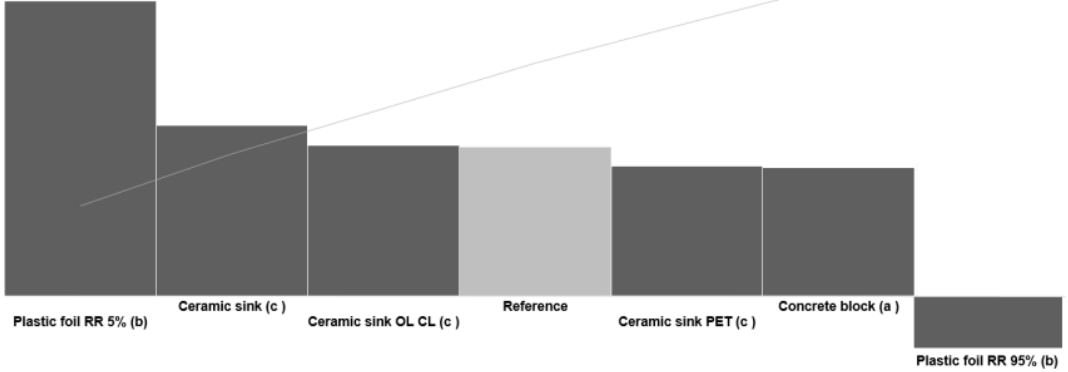

Figure 4. Weighted results (for decision making)

Results for mechanical recycling to concrete blocks (a) indicate overall indicators improvement and reinforce previous research, that recycling to concrete elements is providing valuable environmental benefits. Best variation is registered by $\mathrm{CO}_{2}$, acidification and eutrophication potential indicators.

Results for mechanical recycling of GRP waste to plastic foil (b) tend to be very positive (best scenario), as most considered indicators have clear and positive net flows. Most benefit is obtained for depletion of abiotic resources, acidification potential and ozone depletion (as petroleum-based products are re-used instead of being acquired anew from nature). However, it should be noted that the very positive 
result is an indication of the optimal scenario, where recycling rate stands at $95 \%$. A variation of the scenario is further included, considering a RR of 5\%. The benefits in this case are not as significant. Mechanical recycling has a very high potential for GRP waste and efforts to increase the recycling rate throughout the industry would have definite beneficial results.

The results for mechanical recycling of GRP waste to ceramic sink (c) tend to be favorable, even if the positive net flows are reduced as compared with the plastic foil. The main reason is that PE and PP production is a process with heavier environmental load than that of kaolin, for which less processing is required, respectively the processing has lower environmental impacts comparatively. Most benefit is obtained for eutrophication potential, depletion of abiotic resources and acidification potential. In the close loop scenario (5\% RC of the recyclate is used back to pipe production) results are similar with the already calculated ceramic sink model. Through application of Module D, credits were allocated for replacing kaolin and debits for shredding the pipe at EoL (open loop), as well as credits for shredding the pipe and debits for replacing virgin materials at pipe production input (close loop). A higher $\mathrm{RC}$ may influence total results positively, depending on the impacts of the recycling, compared to the functional equivalence process. In case of the GRP product, it is expected that this influence would be positive but moderate. In the variant where recycled PET resin is used for pipe production, results are better than of the original scenario "Ceramic sink", due to using recycled input. Most benefit is obtained for eutrophication potential, ozone creation and acidification potential.

\section{Conclusions}

Results for mechanical recycling of GRP waste are positive, especially at higher recycling rates. The most favorable method is recycling to plastic foil (as primary petroleum-based resources are saved), followed by recycling to concrete block and ceramic sink. Using of close loop and recycled raw materials brings further environmental benefits. Mechanical recycling remains a strong option for GRP recycling, especially from an environmental perspective. The main challenge remains identifying product applications that can incorporate the GRP powder to satisfactory product quality requirements (e.g. compressive strength, tensile strength, shrinkage, water absorption, density, microstructure, sort-term and long-term performance) and that have market potential (operational cost, demand and distribution channels).

\section{Acknowledgements}

This work was supported by the Technical University of Civil Engineering (UTCB) (Bucharest, Romania) and HOBAS Pipes International GmbH (Klagenfurt, Austria).

\section{References}

Asokan, P, Osmani, M \& Price, A 2009, 'Assessing the recycling potential of glass fibre reinforced plastic waste in concrete and cement composites', Journal of Cleaner Production, vol. 17, pp. 821-829.

Bravo, E, Lucchese, G \& Mioni, F 2014, Recycling Method. Italy, Patent No. WO2014/132184A1. 
EC 2016, EU Environmental Footprint Pilot Phase - Support and documents. Available at: https://webgate.ec.europa.eu/fpfis/wikis/pages [21 February 2017].

EC-EURECOMP 2013, Final Report Summary EURECOMP, Recycling Thermoset Composites of the SST.

Available at: http://cordis.europa.eu/result/rcn/54152_en.html [26 January 2017].

ESS 2016, Extreme Eco Solutions. Available at: http://extreme-ecosolutions.com/ [02 February 2017].

Job, S 2013, 'Recycling glass fiber reinforced composites - history and progress (Part 1)', Reinforced Plastics, vol. 19-23, pp. 19-23.

Pickering, S 2006, 'Recycling technologies for thermoset composite materials current status', Composites, vol. 37, pp. 1206-1215.

Ribeiro, M et al. 2014, 'Mix design process of polyester polymer mortars modified with recycled GFRP waste materials', Composite Structure, vol. 105, pp. 300310.

Rybicka, J, Tiwari, A \& Leeke, G 2016, 'Technology readiness level assessment of composites recycling technologies', Journal of Cleaner Production, vol. 112, pp. 1001-1012.

Vladimirov, V \& Bica, I 2017, 'Circular Economy: Recycling Glass Fibre Reinforced Composites (GRP) According To En 15804 Module D (End-of-life) Through Applied LCA Scenarios', Bucharest, Romania, ARA Romanian Water Association, pp. 157-173.

Wolf, M \& Chomkhamsri, K 2014, "The "Integrated formula" for modelling recycling, energy recovery and reuse in LCA', Berlin, Germany.

Wolf, R 2008, 'Method of Recycling Fiberglass Reinforced Plastics', USA, Patent No. US/2008/021781/ A1.

Yazdanbakhsh, A \& Bank, L 2014, 'A Critical Review of Research on Reuse of Mechanically Recycled FRP Production and End-of-Life Waste for Construction', Polymers, vol. 6, pp. 1810-1826. 